\title{
Selvmord blandt danske scleroseramte
}

\author{
Ved Henrik Brønnum-Hansen, Egon Stenager, Elsebeth Nylev Stenager og Nils Koch-Henriksen
}

\begin{abstract}
Det Danske Scleroseregister har systematisk indsamlet oplysninger om sclerosetilfælde i Danmark. Blandt alle 10.174 scleroseramte, som blev diagnosticeret i perioden 1953-1996 og som er blevet fulgt med hensyn til død frem til 1999, tog 115 deres eget liv. Det forventede antal selvmord i baggrundsbefolkningen var 54 . Scleroseramtes selvmordsrisiko var altså godt og vel dobbelt så høj som i befolkningen generelt. I de første 15 år efter at diagnosen blev stillet, var den forhøjede selvmordsrisiko stort set konstant blandt mænd - godt og vel 2,5 gange det forventede antal. Blandt scleroseramte kvinder var risikoen særlig høj det første år efter, at diagnosen blev stillet (4 gange det forventede) med et fald de efterfølgende år (til 1,8 gange det forventede 15 år efter diagnosen). Den forhøjede selvmordsrisiko blandt scleroseramte var lavest 15-20 år efter diagnosen, men steg herefter, således at risikoen var næsten den dobbelte for personer med sclerose, der havde levet med diagnosen i over 20 år sammenlignet med baggrundsbefolkningen.
\end{abstract}

\section{Indledning}

Denne undersøgelse blev første gang publiceret i oktober 2005 (BrønnumHansen et al., 2005). En tidligere dansk unders $\varnothing$ gelse af scleroseramtes overlevelse viste, at dødeligheden var ca. 3 gange højere blandt scleroseramte end i befolkningen og at overd $\varnothing$ deligheden var forhøjet for alle st $\varnothing$ rre sygdomsgrupper (på nær cancer) og for ulykker og selvmord (Brønnum-Hansen et al., 2004). Psykiske lidelser, specielt depression, forekommer ofte blandt scleroseramte, bl.a. i forbindelse med forværring af sygdommen (McIvor et al., 1984; Sadovnick et al., 1996; Fisk et al., 1998; Chwastiak et al., 2002).

Øget risiko for depression og selvmord vides at være relateret til en række sygdomme (Harris \& Barraclough, 1994; Kleespies et al., 2000; Stenager \& Stenager, 2000). Det at få stillet en alvorlig diagnose, kan i sig selv fremprovokere en psykisk krise, men nogle neurologiske sygdomme kan påvirke det mentale helbred og føre til depressiv tilstand. Derfor kan risikoen for selvmord tænkes at være forhøjet blandt scleroseramte.

Andre undersøgelser tyder på, at der er en sammenhæng mellem sclerose og risiko for selvmord. Dette er vist i en tidligere dansk undersøgelse, hvor risikoen var fordoblet (Stenager et al., 1992) og i en nyere svensk unders $\varnothing$ gelse, som viste en forhøjet risiko for selvmord på 2,3 i forhold til befolkningen generelt (Fredrikson et al., 2003). En endnu højere overrisiko blev fundet i Canada (Sadovnick et al., 1991), mens en finsk unders $\varnothing$ gelse ikke fandt en $\varnothing$ get risiko for selvmord blandt scleroseramte (Sumelahti et al., 2002).

De forskellige resultater i de foreliggende undersøgelser skyldes forskelle i undersøgelsesdesign og metodeproblemer (Stenager \& Stenager, 1992).

Formålet med den foreliggende undersøgelse var at vurdere om risikoen for selvmord blandt danske scleroseramte har ændret sig siden 1950erne. Med den lange registreringsperiode for Det Danske Scleroseregister og en lang opf $\varnothing$ lgning med hensyn til overlevelse og med en systematisk registrering af dødsårsager blandt alle danskere er det muligt at belyse selvmordsrisikoen for danskere, der har været scleroseramt i mange år. I intet andet land findes nationale data, der med samme styrke kan belyse udviklingen i selvmordsrisikoen blandt scleroseramte.

\section{Materiale og metode}

Undersøgelsen er baseret på Scleroseregistret, som - via registerkobling med det Centrale Person Register - indeholder oplysninger om alle dødsfald indtruffet før 1 . august 2000 blandt danske scleroseramte. Fra Dødsårsagsregistret er suppleret med oplysninger om dødsårsager. Materialet omfatter alle scleroseramte, der blev diagnosticeret i perioden 1953-1996 med verificeret diagnose og indberettet til Scleroseregistret før 1. januar 1997.

Alle er fulgt med hensyn til årsagsspecifik dødelighed (Dødsårsagsregistret) frem til 1. januar 1999. Det forventede antal selvmord blev beregnet ved at multiplicere de observerede personår opdelt $\mathrm{i} k \emptyset \mathrm{n}$, alder og kalenderår med de på tilsvarende måde opdelte selvmordsrater i befolkningen. Standardiserede mortalitets ratioer (SMR), som er det observerede antal selvmord divideret med det forventede antal, blev beregnet tillige med $95 \%$-sikkerhedsintervaller herfor. Yderligere detaljer er beskrevet i den originale artikel (Brønnum-Hansen et al., 2005).

\section{Resultater}

Undersøgelsen omfatter 10.174 scleroseramte (4061 mænd og 6113 kvinder), som i alt repræsenterer 160.401 observationsår eller personår. I alt døde 115 scleroseramte på grund af selvmord (63 mænd og 52 kvinder). Det forventede antal selvmord var 54,2 (29,1 mænd og 25,1 kvinder). Antal personer, personår, observerede og forventede antal selvmord opdelt i 3 aldersgrupper ved diagnose er vist i tabel 1 . Tabel 2 viser alder ved selvmord for de 115 selvmordstilfælde.

Samlet set var den forhøjede risiko for selvmord statistisk signifikant med en standardiseret mortalitets ratio (SMR) på 2,12 (95\% sikkerhedsinterval: 1,752,55) og uden nævneværdig forskel mellem mænd og kvinder (tabel 3).

Betydningen af sygdommens varighed er belyst i tabel 3, som viser SMR i 6 perioder efter at diagnosen er stillet. Det fremgår, at den forh $\varnothing$ jede selvmordsrisiko blandt mænd med sclerose var nogenlunde konstant de første 15 år, hvor SMR varierede mellem 2,18 og 2,76. Overrisikoen var lavest 15-20 år efter diagnose $(\mathrm{SMR}=1,33)$, men steg herefter $(\mathrm{SMR}=1,74)$. Samme mønster sås hos kvinder med sclerose, som dog havde en stærkt forh $\varnothing j e t$ risiko det første år efter diagnose $(\mathrm{SMR}=4,03)$. 
Tabel 1

Antal danskere med sclerose diagnosticeret i perioden 1953-1996, personår, observerede og forventede antal selvmord. Opfølgning frem til 1. januar 1999

\begin{tabular}{|l|c|c|c|c|c|}
\hline Køn & $\begin{array}{l}\text { Alder ved } \\
\text { diagnose }\end{array}$ & $\begin{array}{l}\text { Antal sclerose- } \\
\text { ramte under } \\
\text { observation }\end{array}$ & Personår & $\begin{array}{l}\text { Observeret } \\
\text { antal } \\
\text { selvmord }\end{array}$ & $\begin{array}{l}\text { Forventet } \\
\text { antal } \\
\text { selvmord }\end{array}$ \\
\hline \multirow{3}{*}{ Mænd } & $<30$ & 782 & $14.100,9$ & 13 & 5,1 \\
\cline { 2 - 6 } & $30-39$ & 1.284 & $21.947,7$ & 28 & 9,9 \\
\cline { 2 - 6 } & $\geq 40$ & 1.995 & $27.362,1$ & 22 & 14,1 \\
\cline { 2 - 6 } & Alle & 4.061 & $63.410,7$ & 63 & 29,1 \\
\hline \multirow{3}{*}{ Kvinder } & $<30$ & 1.360 & $24.397,0$ & 11 & 4,3 \\
\cline { 2 - 6 } & $30-39$ & 1.829 & $31.058,5$ & 22 & 7,9 \\
\cline { 2 - 6 } & $\geq 40$ & 2.924 & $41.534,9$ & 19 & 12,9 \\
\cline { 2 - 6 } & Alle & 6.113 & $96.990,4$ & 52 & 25,1 \\
\hline \multirow{2}{*}{ kegge } & $<30$ & 2.142 & $38.497,9$ & 24 & 9,4 \\
\cline { 2 - 6 } & $30-39$ & 3.113 & $53.006,2$ & 50 & 17,8 \\
\cline { 2 - 6 } & $\geq 40$ & 4.919 & $68.897,0$ & 41 & 27,0 \\
\hline \multirow{3}{*}{ Alle } & 10.174 & $160.401,1$ & 115 & 54,2 \\
\hline
\end{tabular}

Tabel 2

Alder ved d $\varnothing \mathrm{d}$ blandt scleroseramte danskere der har begået selvmord

\begin{tabular}{|c|c|c|r|r|r|r|}
\hline \multirow{2}{*}{$\begin{array}{l}\text { Alder } \\
\text { ved } \\
\text { selvmord }\end{array}$} & \multicolumn{2}{|c|}{ Mænd } & \multicolumn{2}{c|}{ Kvinder } & \multicolumn{2}{c|}{ Begge køn } \\
\cline { 2 - 7 } & Antal & $\%$ & Antal & $\%$ & Antal & $\%$ \\
\hline$<40$ & 13 & 20,6 & 12 & 23,1 & 25 & 21,7 \\
\hline $40-44$ & 17 & 27,0 & 4 & 7,7 & 21 & 18,3 \\
\hline $45-49$ & 9 & 14,3 & 10 & 19,2 & 19 & 16,5 \\
\hline $50-54$ & 10 & 15,9 & 10 & 19,2 & 20 & 17,4 \\
\hline$\geq 55$ & 14 & 22,2 & 16 & 30,8 & 30 & 26,1 \\
\hline Alle & 63 & 100,0 & 52 & 100,0 & 115 & 100,0 \\
\hline
\end{tabular}

Tabel 3

Standardiserede mortalitets ratioer (SMR) for selvmord i forskellige perioder efter diagnose

\begin{tabular}{|c|c|c|c|c|}
\hline \multirow{2}{*}{$\begin{array}{c}\text { Ar efter } \\
\text { diagnose }\end{array}$} & \multicolumn{4}{|c|}{ SMR (95 \% sikkerhedsinterval) } \\
\cline { 2 - 5 } & Mænd & Kvinder & Begge køn \\
\hline $0-1$ & $2,47(0,67-6,32)$ & $4,03(1,31-9,41)$ & $3,15(1,44-5,97)$ \\
\hline $1-5$ & $2,18(1,19-3,66)$ & $2,62(1,40-4,48)$ & $2,37(1,56-3,45)$ \\
\hline $5-10$ & $2,76(1,66-4,31)$ & $2,18(1,13-3,80)$ & $2,50(1,70-3,55)$ \\
\hline $10-15$ & $2,29(1,18-3,99)$ & $1,78(0,77-3,50)$ & $2,05(1,25-3,17)$ \\
\hline $15-20$ & $1,33(0,43-3,10)$ & $0,85(0,18-2,49)$ & $1,10(0,47-2,16)$ \\
\hline $20-45$ & $1,74(0,80-3,31)$ & $2,04(1,02-3,65)$ & $1,89(1,16-2,93)$ \\
\hline $0-45$ & $2,16(1,66-2,77)$ & $2,07(1,55-2,72)$ & $2,12(1,75-2,55)$ \\
\hline
\end{tabular}

SMR blandt scleroseramte, som blev diagnosticeret før de blev 30 år, var 2,55 for begge køn. For dem, der var 30-39 år, da diagnosen blev stillet, var SMR 2,81. SMR var 1,52 for scleroseramte, som fik stillet diagnosen da de var 40 år eller ældre, hvilket var statistisk signifikant lavere end for aldersgruppen 30-39 år (tabel 4).

Tabel 5 viser SMR-estimater for scleroseramte diagnosticeret i perioderne 1953-1961, 1962-1970, 1971-1979 og 1980-1988 og med en opfølgningstid på 10 år. Det fremgår, at scleroseramtes forh øjede selvmordsrisiko ikke har ændret sig signifikant, men at der har været en tendens til stigning fra 1971-1979 til 1980-1988, specielt blandt kvinder.

\section{Diskussion}

I Danmark er selvmordsrisikoen st $\varnothing$ rre for mænd end for kvinder (Helweg-Larsen \& Juel, 2000). Dette gælder også blandt scleroseramte. Vi fandt ikke nogen væsentlig kønsforskel i forh $\varnothing$ jet selvmordsrisiko blandt scleroseramte; dog sås en st $\varnothing$ rre overrisiko for kvinder end for mænd det første år efter diagnosetidspunkt. Men risikoen for selvmord er stadig st $\varnothing$ rre blandt scleroseramte mænd end scleroseramte kvinder. Stigningen i SMR for selvmord fra 1971-1979 til 1980-1988 (tabel 5) kan delvis forklares ved det markante fald siden 1980 i selvmordsraten i Danmark, i særdeleshed blandt danske kvinder (Juel, 2004). Således ville SMR falde fra 2,69 til 2,41 og fra 3,89 til 3,17 for mænd henholdsvis kvinder diagnosticeret i 1980-1988, hvis befolkningens selvmordsrater for 1975-1979 blev anvendt ved beregningerne for de efterfølgende perioder.

Den danske scleroseforenings tilbud om psykologhjælp til scleroseramte, som blev introduceret i 1986, kan ikke forventes at have en synlig effekt på forekomsten af fuldbyrdet selvmord. Nogle har udtrykt bekymring for at behandling med beta-interferon kunne $\varnothing$ ge risikoen for depression. Dette har ikke kunnet beeller afkræftes, da behandlingen først blev indført i 1996 og opf $\varnothing$ lgningstiden har været for kort. Siden 1990 var der 9 selvmord i 1990-1992, 18 i 1993-1995 og 11 i 1996-1998. 


\begin{tabular}{|c|c|c|c|}
\hline \multirow{2}{*}{$\begin{array}{l}\text { Alder ved } \\
\text { diagnose }\end{array}$} & \multicolumn{3}{|c|}{ SMR (95\% sikkerhedsinterval) } \\
\hline & Mæn & Kvinder & Begge køn \\
\hline$<30$ & $2,55 \quad(1,36-4,36)$ & $2,55 \quad(1,27-4,56)$ & $2,55 \quad(1,63-3,79)$ \\
\hline $30-39$ & $2,82 \quad(1,87-4,08)$ & $2,79(1,75-4,22)$ & $2,81 \quad(2,08-3,70)$ \\
\hline$\geq 40$ & $1,56(0,98-2,36)$ & $1,47 \quad(0,89-2,30)$ & $1,52(1,09-2,06)$ \\
\hline Alle & $2,16(1,66-2,77)$ & $2,07 \quad(1,55-2,72)$ & $2,12(1,75-2,55)$ \\
\hline
\end{tabular}

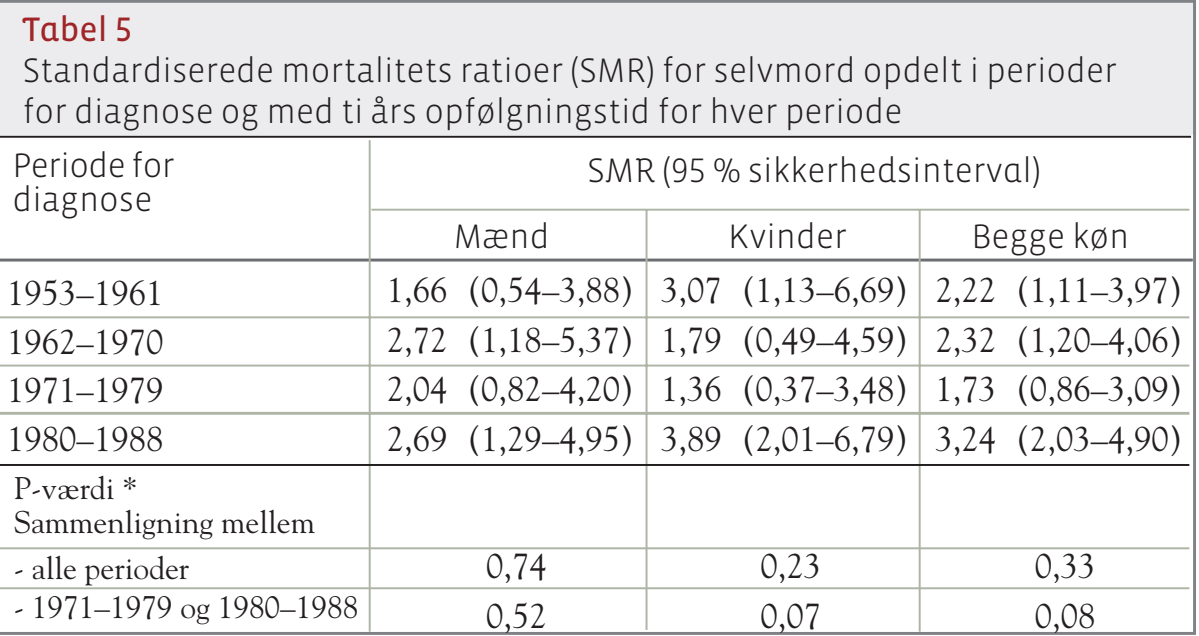

* De statistiske tests er baseret på Cox regressions modeller, hvor der er taget højde for scleroseramtes og baggrundsbefolkningens alder og udviklingen i baggrundsbefolkningens selvmordsrater.

Den lange opfølgningstid gjorde det muligt at vurdere selvmordsrisikoen blandt scleroseramte, der har levet længe med sygdommen, heriblandt patienter for hvem sygdommen er blevet en hård belastning. Vi fandt, at SMR var højere for scleroseramte, som var blevet diagnosticeret mere end 20 år tidligere end for dem, der havde levet med diagnosen i 15-20 år, om end forskellen ikke var statistisk signifikant. Den generelle konklusion fra tidligere unders $\varnothing$ gelser om selvmordsrisikoen blandt scleroseramte har været, at risikoen var st $\varnothing$ rst kort tid efter at diagnosen blev stillet (Stenager et al., 1992; Fredrikson et al., 2003).

Vi fandt, at risikoen forblev $h ø j$ mange år efter diagnosetidspunktet, hvilket også blev rapporteret i en retrospektiv undersøgelse (Berman \& Samuels, 1993). Da Scleroseregistret ikke inkluderer systematisk indsamlede oplysninger om disabilitet og andre oplysninger om sygdomsforløb, har det ikke været muligt at under- søge effekten af sygdommens progression på selvmordsrisikoen. Men tidligere unders $\varnothing$ gelser har identificeret forhold, der kan være medvirkende til selvmord og selvmordsfors $\varnothing$ g. Størst risiko sås hos mænd med psykisk sygdom, depression og forværret sygdomstilstand; for kvinder sås ingen tydelige sammenhænge (Stenager et al., 1996). Social isolation, alvorlig depression og alkoholmisbrug blev identificeret som prædiktorer for selvmordsfors $\varnothing \mathrm{g}$ (Feinstein, 2002).

En neurologisk sygdom som sclerose kan påvirke patienten mentalt og føre til depression og selvmord. I så fald kunne en $\varnothing$ get risiko for selvmord være til stede efter sygdomsdebut allerede $f \varnothing r$ diagnosen er stillet. Det er ikke muligt at unders $\varnothing$ ge denne hypotese, fordi registrering i Scleroseregistret forudsætter, at diagnosen er stillet. Den eneste mulighed for registrering af et selvmord hos en scleroseramt, der har taget sit eget liv før diagnosen blev stillet, er via obduktion, hvor opmærksomheden ikke specielt er rettet mod, om der er tegn på, at en afd $\varnothing$ d havde sclerose. Blandt denne unders $\varnothing$ gelses 115 selvmordstilfælde blev sclerosediagnosen bekræftet ved obduktion i 9 tilfælde og alle var diagnosticeret før selvmordet.

Der kunne heller ikke konstateres forskel i tidsinterval mellem debut og diagnose blandt dem der begik selvmord og dem der ikke gjorde.

Der kan være en risiko for, at selvmord blandt alvorligt syge bliver overset og at lægen, der udfylder dødsattesten, angiver sclerose som dødsårsag for en sclerosepatient, der faktisk begik selvmord. Der gennemf $\varnothing$ res ikke rutinemæssig obduktion i disse tilfælde. Denne mulige fejlkilde kan betyde, at scleroseramtes forh $\varnothing$ jede selvmordsrisiko undervurderes.

Skønt depression er hyppig hos scleroseramte, er der risiko for, at patientens læge ikke er tilstrækkelig opmærksom herpå. Resultaterne af vores unders $\varnothing$ gelse understreger betydningen af $\varnothing$ get opmærksomhed på scleroseramtes psykiske helbred både umiddelbart ved sygdomsdebut og diagnose og i det senere sygdomsforl $\varnothing b$.

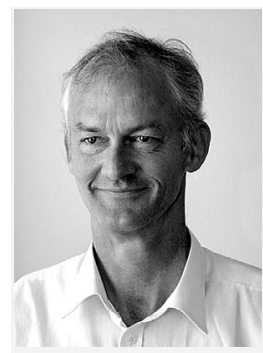

Henrik Brønnum-

Hansen er statistiker og programkoordinator for "Forskningsprogrammet for registerforskning i udvalgte sygdomme og helbredsproblemer" på Statens Institut for Folkesundhed, København. Hans arbejdsopgaver/-områder er bl.a. statistiske analyser af incidens, prævalens og dødelighed af specifikke sygdomme, specielt baseret på registerdata, analyser af udviklingen i forekomst og effekt af risikofaktorer på sygdom og dødelighed, scleroseepidemiologi mv.

Egon Stenager er klinikchef ved Scleroseklinikken i Esbjerg og Vejle, Sydvestjysk Sygehus, Esbjerg.

Elsebeth Nylev Stenager er lektor ved Institut for Sundhedstjenesteforskning, Almen Medicin, Syddansk Universitet.

Nils Koch-Henriksen er overlæge ved Neurologisk afdeling, Aalborg Sygehus Nord.

Referencer, se s.28. 
Berman, A., \& Samuels, L. (1993). Suicide among people with multiple sclerosis. Journal of neurologic rehabilitation 7: 53-62.

Brønnum-Hansen, H., Stenager, E., Stenager, E.N., \& Koch-Henriksen, N. (2005). Suicide among Danes with multiple sclerosis. Journal of Neurology, Neurosurgery, and Psychiatry 76: 1457-9.

Brønnum-Hansen, H., Koch-Henriksen, N., \& Stenager, E. (2004). Trends in survival and cause of death in Danish patients with multiple sclerosis. Brain 127: 844-50.

Chwastiak, L., Ehde, D.M., Gibbons, L.E., Sullivan, M., Bowen, J.D., \& Kraft, G.H. (2002). Depressive symptoms and severity of illness in multiple sclerosis: epidemiologic study of a large community sample. The American journal of psychiatry 159: 1862-8.

Feinstein, A. (2002). An examination of suicidal intent in patients with multiple sclerosis. Neurology 59: 674-8.

Fisk, J.D., Morehouse, S.A., Brown, M.G., Skedgel, C., \& Murray, T.J. (1998). Hospital-based psychiatric service utilization and morbidity in multiple sclerosis. The Canadian journal of neurological sciences 25: 230-5.

Fredrikson, S., Cheng, Q., Jiang, G.X., \& Wasserman, D. (2003). Elevated suicide risk among patients with multiple sclerosis in Sweden. Neuroepidemiology 22: 146-52.

Harris, E.C., \& Barraclough, B.M. (1994). Suicide as an outcome for medical disorders. Medicine 73: 281-96.

Helweg-Larsen. K., \& Juel, K. (2000). Sex differences in mortality in Denmark during half a century, 1943-92. Scandinavian Journal of Public Health 28: 214-21.

Juel, K. (2004). Dødelighed i Danmark siden 1900. København, Statens Institut for Folkesundhed.
Kleespies, P.M., Hughes, D.H., \& Gallacher, F. (2000). Suicide in the medically and terminally ill: psychological and ethical considerations. Journal of clinical psychology 56: 1153-71.

McIvor, G.P., Riklan, M., \& Reznikoff, M. (1984). Depression in multiple sclerosis as a function of length and severity of illness, age, remissions, and perceived social support. Journal of clinical psychology 40: 1028-33.

Sadovnick, A.D., Eisen, R.N., Ebers, G.C., \& Paty, D.W. (1991). Cause of death in patients attending multiple sclerosis clinics. Neurology 41: 1193-6.

Sadovnick, A.D., Remick, R.A., Allen, J., Swartz, E., Yee, I.M.L., Eisen, K., Farquhar, R., Hashimoto, S.A., Hooge, J., Kastrukoff, L.F., Morrison, W., Nelson, J., Oger, J., \& Paty. D.W. (1996).

Depression and multiple sclerosis. Neurology 46: 628-32.

Stenager, E.N., Stenager, E., Koch-Henriksen, N., Brønnum-Hansen, H., Hyllested, K., Jensen, K., \& Bille-Brahe, U. (1992). Suicide and multiple sclerosis: an epidemiological investigation. Journal of Neurology, Neurosurgery, and Psychiatry 55: 542-5.

Stenager, E.N., \& Stenager, E. (1992).

Suicide and patients with neurologic diseases: methodologic problems. Archives of neurology 49: 1296-303.

Stenager, E.N., Koch-Henriksen, N., Stenager, E. (1996). Risk factors for suicide in multiple sclerosis. Psychotherapy and psychosomatics 65: 86-90.

Stenager, E.N., \& Stenager, E. (2000). Physical illness and suicidal behaviour. In: Hawton $K$, van Heeringen $\mathrm{K}$, eds. The international handbook of suicide and suicide attempt. London: John Wiley and Sons Ltd, 403-20.

Sumelahti, M.-L., Tienari, P.J., Wikström, J., Salminen, T.M., \& Hakama, M. (2002). Survival of multiple sclerosis in Finland between 1964 and 1993. Multiple Sclerosis 8: 350-5. 